Aplikasi Peramalan Jumlah Pemohon Paspor Menggunakan Metode Double Exponential Smoothing Pada Kantor Imigrasi Kelas II Kota Lhokseumawe

\title{
APLIKASI PERAMALAN JUMLAH PEMOHON PASPOR MENGGUNAKAN METODE DOUBLE EXPONENTIAL SMOOTHING PADA KANTOR IMIGRASI KELAS II KOTA LHOKSEUMAWE
}

\author{
Eva Darnila ${ }^{1}$, Asrianda ${ }^{2}$, Rauzatul Jannah ${ }^{3}$ \\ Teknik Informatika Universitas Malikussaleh \\ Jl. Kampus Unimal BI Blang Pulo, Aceh Utara, Indonesia \\ rauzatuljannah808@gmail.com ${ }^{3}$
}

\begin{abstract}
Abstrak
Abstrak - Setiap tahunnya jumlah pemohon paspor dikantor imigrasi selalu meningkat (kantor imigrasi kelas II Kota Lhokseumawe). peningkatan jumlah pemohon paspor ini akan berdampak pada kesediaan sarana, prasarana, maupun pelayanan pengurusan paspor yang sering mencapai 500 - 600 buah paspor setiap bulannya ditahun 2016. Penelitian peramalan ini dilakukan dengan menggunakan metode double exponential smoothing. Perhitungan akurasi dilakukan dengan Mean Absolute Percentage Error (MAPE). Data yang digunakan sebanyak 72 data permohonan paspor baru mulai dari bulan januari 2016 sampai desember 2018 perjenis laki - laki dan perempuan didapatkan dari kantor imigrasi kelas II kota Lhokseumawe. Dari penelitian ini pengujian pada tahun 2018 didapatkan nilai parameter untuk double exponential smoothing adalah $a=0.2$. Dari nilai parameter tersebut didapatkan nilai SSE sebesar $=2356.833705$, nilai MSE sebesar $=1178.416852$ dan MAPE sebesar $=5,585627855$.
\end{abstract}

Kata Kunci : Peramalan, Paspor, Double Exponential Smoothing, Mean Absolute Percentage Error (MAPE)

\section{Pendahuluan}

Pada dasarnya, setiap individu yang melakukan perjalanan keluar negeri memiliki tujuan masing - masing baik secara privat maupun non privat. Intensitas kerjasama antar negara dirasakan terus meningkat, tidak saja dalam sektor perdagangan tetapi juga 
dalam sektor - sektor strategis lainnya seperti pendidikan dan pariwisata. Salah satu dokumen penting yang digunakan sebagai izin resmi untuk memasuki teritorial suatu negara adalah paspor.

Kantor imigrasi kelas II kota Lhokseumawe merupakan lembaga yang memberikan pelayanan yang bergerak dalam bidang keimigrasian, salah satunya memberikan pelayanan pengurusan paspor. Peningkatan jumlah pemohon paspor ini akan berdampak pada kesediaan sarana, prasarana, maupun pelayanan pengurusan paspor yang sering mencapai 500 - 900 buah paspor setiap bulannya di tahun 2016.

Dari permasalahan di atas, penulis menawarkan solusi yaitu dengan meramalkan jumlah pemohon paspor. Ada beberapa metode yang digunakan untuk menyelesaikan masalah ini, diantaranya adalah metode double exponential smoothing sebagai metode yang akan diuji dalam penelitian ini. Metode ini menggunakan nilai parameter yang didapat dari perhitungan secara trial dan error untuk menghasilkan nilai akurat. Apabila data yang digunakan banyak dalam perhitungan peramalannya maka MAPE (Mape Absolute Percentage Error) peramalannya akan semakin kecil begitu juga sebaliknya.

Berdasarkan uraian diatas, penulis melakukan penelitian tugas akhir ini dengan judul "Aplikasi peramalan jumlah pemohon paspor menggunakan metode double exponential smoothing pada kantor imigrasi kelas II kota lhokseumawe.

\section{Metode Penelitian}

\subsection{Pengertian paspor}

Paspor merupakan dokumen mutlak yang harus dimiliki oleh setiap warga negara yang ingin bepergian antar negara. Didalam paspor harus memuat data diri, foto pemegang paspor, lembar lembar untuk pencatatan dan tanda keberangkatan atau kedatangan oleh petugas keimigrasian dari asal keberangkatan dan negara yang dikunjunginya. (Nasdaniar, 2017).

Berikut adalah jumlah pemohon paspor yang ada dikantor Imigrasi kelas II kota Lhokseumawe januari tahun 2016 sampai desember 2018 : 
Aplikasi Peramalan Jumlah Pemohon Paspor Menggunakan Metode Double Exponential Smoothing Pada Kantor Imigrasi Kelas II Kota

Tabel 1. Pemohon paspor

\begin{tabular}{|c|c|c|c|}
\hline \multirow{2}{*}{ Bulan } & \multicolumn{3}{|c|}{ Pemohon Paspor } \\
\cline { 2 - 4 } & 2016 & 2017 & 2018 \\
\hline Januari & 943 & 599 & 705 \\
\hline Februari & 741 & 518 & 674 \\
\hline Maret & 650 & 579 & 656 \\
\hline April & 730 & 579 & 558 \\
\hline Mei & 593 & 439 & 447 \\
\hline Juni & 500 & 312 & 317 \\
\hline Juli & 1.155 & 557 & 708 \\
\hline Agustus & 899 & 473 & 376 \\
\hline September & 907 & 452 & 451 \\
\hline Oktober & 825 & 576 & 508 \\
\hline November & 671 & 567 & 475 \\
\hline Desember & 574 & 496 & 510 \\
\hline
\end{tabular}

Sumber : Kantor Imigrasi

\subsection{Metode Double Exponential Smoothing}

Metode ini dikemukakan oleh Brown's untuk mengatasi perbedaan yang muncul antara data aktual dan nilai peramalan apabila ada trend pada poltnya. Dasar pemikiran dari penulisan eksponensial linier (Linier Moving Average), karena kedua nilai pemulusan tunggal dan ganda ketunggalan dari data yang sebenarnya bilamana terdapat unsur trend, perbedaan antara nilai pemulusan tunggal dan ganda ditambahkan kepada nilai pemulusan dan disesuaikan untuk trend. Dan digunakan untuk peramalan dengan cara menentukan besarnya a (alpha) secara trial dan error antara 0 sampai dengan 1 dan dilakukan proses smoothing dua kali.

Dengan rumus :

$S_{t}^{\prime}=a X_{t}+(1-a) S_{t}^{\prime}-1$

Dimana, Keterangan sebagai berikut : 


$$
\begin{array}{cl}
S_{t}^{\prime} & : \text { Single exponential smoothing } \\
\mathrm{a} & \text { : Alpha (parameter antara nol dan } 1) \\
X_{t}+(1-\mathrm{a}) & \text { : Nilai aktual time series } \\
1 & : \text { Pemulusan nilai observasi } \\
S_{t}^{\prime \prime}=\mathrm{a} S_{t}^{\prime}+(1-\mathrm{a}) S_{t}^{\prime \prime}-1 \ldots \ldots \ldots \ldots \ldots \ldots \ldots \ldots \ldots \ldots \ldots \ldots \ldots \ldots \ldots \ldots \ldots \ldots \ldots \ldots \ldots \ldots \ldots \ldots
\end{array}
$$

Dimana, Keterangan sebagai berikut :

$$
\begin{aligned}
& S_{t}^{\prime \prime} \quad: \text { Double exponential smoothing } \\
& \text { a } \quad \text { : Alpha (parameter antara nol dan 1) } \\
& X_{t}+(1-a) \quad \text { : Nilai aktual time series } \\
& 1 \quad \text { : Pemulusan nilai observasi } \\
& a_{t}=2 S_{t}^{\prime}-S_{t}^{\prime \prime}
\end{aligned}
$$

Dimana, Keterangan sebagai berikut :

$$
\begin{array}{cl}
a_{t} & : \text { Konstanta } \\
S_{t}^{\prime} & : \text { Single Exponential Smoothing } \\
S_{t}^{\prime \prime} & : \text { Double Exponential Smoothing } \\
b_{t}=\frac{\mathrm{a}}{\mathrm{a}-1}\left(S_{t}^{\prime}-S_{t}^{\prime \prime}\right) \ldots \ldots \ldots \ldots \ldots \ldots \ldots \ldots \ldots \ldots \ldots \ldots \ldots \ldots \ldots \ldots \ldots
\end{array}
$$

Dimana, Keterangan sebagai berikut :

$b_{t} \quad$ : Koefisien trend

a : Alpha (parameter antara nol dan 1)

$S_{t}^{\prime} \quad$ : Single Exponential Smoothing

$S_{t}^{\prime \prime} \quad$ : Double Exponential Smoothing

$$
S_{t+m}=a_{t}-b_{t}
$$

Dimana, Keterangan sebagai berikut :

$S_{t+m} \quad$ : Hasil peramalan ke $-m$

$m$ : Jumlah periode ke muka yang akan diramalkan

$a_{t} \quad:$ Konstanta 
Aplikasi Peramalan Jumlah Pemohon Paspor Menggunakan Metode Double Exponential Smoothing Pada Kantor Imigrasi Kelas II Kota

$b_{t} \quad:$ Koefisien trend

\subsection{Mean Absolute Percentage Error (MAPE)}

Mean Absolute Percentage Error (MAPE) merupakan suatu perhitungan evaluasi, MAPE digunakan untuk mengukur seberapa tepat atau akurat suatu prediksi yang ring digunakan (Kim \& Kim, 2016). Berikut ini adalah rumus perhitungan MAPE. Dengan rumus :

$M A P E=\frac{100}{n} \sum_{i=0}^{n}\left|\frac{\hat{y} i-y i}{y i}\right|$

Dimana, keterangan sebagai berikut :

$\hat{y} i \quad$ : Hasil peramalan

yi : Nilai aktual

$n \quad$ : Banyaknya data yang diuji

\section{Hasil dan Pembahasan}

Sistem yang akan dibangun akan melakukan perhitungan peramalan berdasarkan jumlah pemohon paspor mulai dari bulan januari 2016 sampai desember 2018. Output dari aplikasi ini adalah trend grafik hasil peramalan yang dihitung dan diproses menggunakan metode double exponential smoothing. Sistem yang akan dibangun dapat menunjukkan hasil jumlah pemohon paspor di tahun kedepannya dengan tampilan trend grafik sehingga memudahkan pengguna melihat titik terendah dan titik tertinggi jumlah pemohon paspor dari suatu peramalan sehingga memudahkan pengguna memperkirakan banyaknya jumlah pemohon paspor dan dapat mempersiapkan penyediaan paspor agar sesuai dengan jumlah pemohon paspor. 


\subsection{Usecase Diagram}

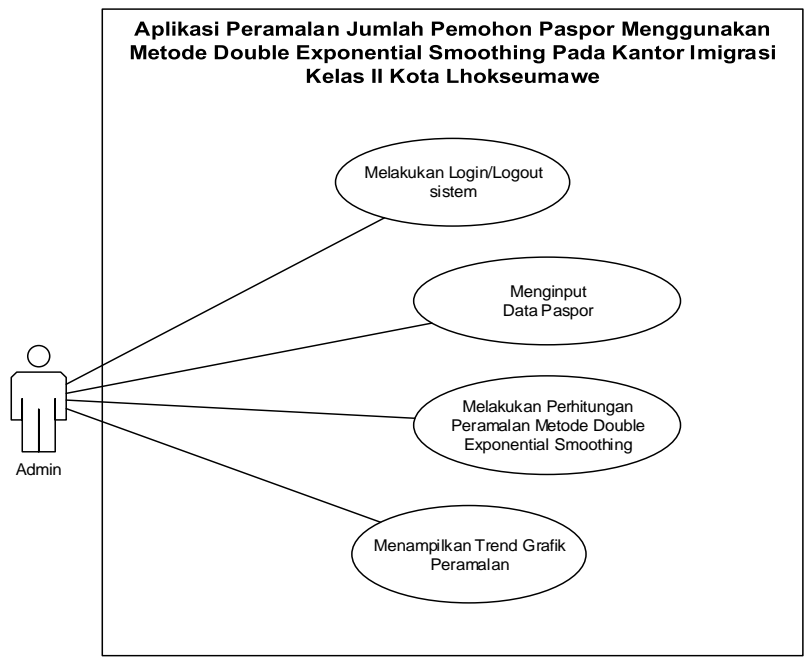

Gambar 1. Usecase Diagram

Keterangan:

Admin melakukan login sistem. Setelah itu, admin menginput data paspor yaitu data permohonan paspor baru dari januari 2016 sampai desember 2018. Kemudian admin melakukan perhitungan peramalan metode double exponential smoothing. Langkah selanjutnya menampilkan trend grafik hasil peramalan. Admin melakukan logout sistem.

\subsection{Perhitungan Peramalan Jumlah pemohon Paspor}

Langkah-langkah perhitungan peramalan jumlah pemohon paspor menggunakan metode Double Exponential Smoothing antara lain dijelaskan sebagai berikut:

1. Menghitung single exponential smoothing

$$
\begin{aligned}
& S_{1}^{\prime}=943 \\
& S_{2}^{\prime}=(0,2) 741+(0,8) 943=148,2+754,4=902,6 \\
& S_{3}^{\prime}=(0,2) 650+(0,8) 902,6=130+722,08=852,08
\end{aligned}
$$


Aplikasi Peramalan Jumlah Pemohon Paspor Menggunakan Metode Double Exponential Smoothing Pada Kantor Imigrasi Kelas II Kota

$$
\begin{aligned}
& S_{4}^{\prime}=(0,2) 730+(0,8) 852,08=146+681,664=827,664 \\
& S_{5}^{\prime}=(0,2) 593+(0,8) 827,664=118,6+662,1312=780,7312
\end{aligned}
$$

2. Menghitung double exponential smoothing

$$
\begin{aligned}
& S_{1}^{\prime \prime}=943 \\
& S_{2}^{\prime \prime}=(0,2) 902,6+(0,8) 943=180,52+754,4=934,92 \\
& S_{3}^{\prime \prime}=(0,2) 852,08+(0,8) 934,92=170,416+747,936=918,352 \\
& S_{4}^{\prime \prime}=(0,2) 827,664+(0,8) 918,352=165,5328+734,6816= \\
& \quad 900,2144 \\
& S_{5}^{\prime \prime}=(0,2) 780,7312+(0,8) 900,2144=156,14624+720,17152 \\
& =876,31776
\end{aligned}
$$

3. Menentukan besarnya nilai konstanta (at)

$a 1=943$

$a 2=2 \times 902,6-934,92=870,28$

$a 3=2 \times 852,08-918,35=785,808$

$a 4=2 \times 827,664-900,2144=755,1136$

$a 5=2 \times 780,7312-876,31776=685,14464$

4. Menentukan besarnya koefisien trend $(\beta t)$

$\beta 1=0$

$\beta 2=\frac{0,2}{0.8}(902,6-934,92)=-8,08$

$\beta 3=\frac{0,2}{0.8}(852,08-918,352)=-16,568$

$\beta 4=\frac{0,2}{0.8}(827,664-900,2144)=-18,1376$

$\beta 5=\frac{0,2}{0.8}(780,7312-876,31776)=-23,89664$

5. Menentukan besar nilai peramalan

$$
\begin{aligned}
& S_{t 1}=943 \\
& S_{t 2}=870,28+-8,08=862,2 \\
& S_{t 3}=785,808+-16,568=769,24 \\
& S_{t 4}=755,1136+-18,1376=736,976 \\
& S_{t 5}=685,14464+-23,89664=661,248
\end{aligned}
$$

Tabel 2. Permohonan paspor baru (double exponential smoothing)

\begin{tabular}{|c|c|c|c|c|c|c|c|c|c|}
\hline $\begin{array}{c}\text { Tahu } \\
\mathbf{n}\end{array}$ & Bulan & $\begin{array}{c}\text { Nila } \\
\mathrm{i}\end{array}$ & $\begin{array}{c}\text { Smoothing } \\
\mathbf{1}\end{array}$ & $\begin{array}{c}\text { Smoothing } \\
\mathbf{2}\end{array}$ & Konstanta & Slope & $\begin{array}{c}\text { Hasil } \\
\text { Ramalan }\end{array}$ & Error $^{2}$ & $\begin{array}{c}\text { ABS FC } \\
\text { error }\end{array}$ \\
\hline
\end{tabular}




\begin{tabular}{|c|c|c|c|c|c|c|c|c|c|}
\hline 2016 & Januari & 943 & 943 & 943 & 943 & 0 & 943 & 0 & 0 \\
\hline & Februari & 741 & 943 & 943 & 943 & 0 & 943 & 40804 & $\begin{array}{r}27.2604588 \\
4 \\
\end{array}$ \\
\hline & Maret & 650 & 902.6 & 934.92 & 870.28 & -8.08 & 862.2 & $\begin{array}{r}45028.8 \\
4 \\
\end{array}$ & $\begin{array}{r}32.6461538 \\
5 \\
\end{array}$ \\
\hline & April & 730 & 852.08 & 918.352 & 785.808 & -16.568 & 769.24 & $\begin{array}{r}1539.77 \\
8 \\
\end{array}$ & $\begin{array}{r}5.37534246 \\
6 \\
\end{array}$ \\
\hline & Mei & 593 & 827.664 & 900.2144 & 755.1136 & -18.1376 & 736.976 & $\begin{array}{r}20729.0 \\
9 \\
\end{array}$ & $\begin{array}{r}24.2792580 \\
1 \\
\end{array}$ \\
\hline & Juni & 500 & 780.7312 & 876.31776 & 685.14464 & -23.89664 & 661.248 & $\begin{array}{r}26000.9 \\
2 \\
\end{array}$ & 32.2496 \\
\hline & Juli & $\begin{array}{c}115 \\
5\end{array}$ & 724.58496 & 845.9712 & 603.19872 & -30.34656 & 572.85216 & $\begin{array}{r}338896 . \\
1 \\
\end{array}$ & $\begin{array}{r}50.4024103 \\
9 \\
\end{array}$ \\
\hline & Agustus & 899 & 810.667968 & $\begin{array}{c}838.910553 \\
6\end{array}$ & $\begin{array}{c}782.425382 \\
4\end{array}$ & -7.0606464 & 775.364736 & $\begin{array}{r}15285.6 \\
8\end{array}$ & $\begin{array}{r}13.7525321 \\
5\end{array}$ \\
\hline & $\begin{array}{c}\text { Septemb } \\
\text { er }\end{array}$ & 907 & $\begin{array}{c}828.334374 \\
4 \\
\end{array}$ & $\begin{array}{c}836.795317 \\
8 \\
\end{array}$ & 819.873431 & $\begin{array}{c}- \\
2.11523584 \\
\end{array}$ & $\begin{array}{c}817.758195 \\
2 \\
\end{array}$ & 7964.1 & $\begin{array}{r}9.83922875 \\
4 \\
\end{array}$ \\
\hline & Oktober & 825 & $\begin{array}{c}844.067499 \\
5 \\
\end{array}$ & $\begin{array}{c}838.249754 \\
1 \\
\end{array}$ & $\begin{array}{c}849.885244 \\
9 \\
\end{array}$ & $\begin{array}{c}1.45443635 \\
2 \\
\end{array}$ & $\begin{array}{c}851.339681 \\
3 \\
\end{array}$ & $\begin{array}{r}693.778 \\
8 \\
\end{array}$ & 3.19268864 \\
\hline & $\begin{array}{c}\text { Novembe } \\
r\end{array}$ & 671 & $\begin{array}{c}840.253999 \\
6 \\
\end{array}$ & $\begin{array}{c}838.650603 \\
2\end{array}$ & 841.857396 & $\begin{array}{c}0.40084910 \\
1 \\
\end{array}$ & $\begin{array}{c}842.258245 \\
1 \\
\end{array}$ & $\begin{array}{r}29329.3 \\
9 \\
\end{array}$ & $\begin{array}{r}25.5228383 \\
2 \\
\end{array}$ \\
\hline & $\begin{array}{c}\text { Desembe } \\
\mathrm{r}\end{array}$ & 574 & $\begin{array}{c}806.403199 \\
7\end{array}$ & $\begin{array}{c}832.201122 \\
5\end{array}$ & $\begin{array}{c}780.605276 \\
9\end{array}$ & -6.4494807 & $\begin{array}{c}774.155796 \\
2\end{array}$ & $\begin{array}{r}40062.3 \\
4 \\
\end{array}$ & $\begin{array}{r}34.8703477 \\
7 \\
\end{array}$ \\
\hline 2017 & Januari & 599 & $\begin{array}{c}759.922559 \\
8 \\
\end{array}$ & 817.74541 & $\begin{array}{c}702.099709 \\
6 \\
\end{array}$ & $\begin{array}{c}- \\
14.4557126 \\
\end{array}$ & 687.643997 & $\begin{array}{r}7857.75 \\
8 \\
\end{array}$ & $\begin{array}{r}14.7986639 \\
4 \\
\end{array}$ \\
\hline & Februari & 518 & $\begin{array}{c}727.738047 \\
8 \\
\end{array}$ & $\begin{array}{c}799.743937 \\
5 \\
\end{array}$ & $\begin{array}{c}655.732158 \\
1 \\
\end{array}$ & 18.0014724 & $\begin{array}{c}637.730685 \\
6 \\
\end{array}$ & $\begin{array}{r}14335.4 \\
4 \\
\end{array}$ & $\begin{array}{r}23.1140319 \\
8 \\
\end{array}$ \\
\hline & Maret & 579 & $\begin{array}{c}685.790438 \\
2 \\
\end{array}$ & $\begin{array}{c}776.953237 \\
7\end{array}$ & $\begin{array}{c}594.627638 \\
8 \\
\end{array}$ & 22.7906999 & 571.836939 & $\begin{array}{r}51.3094 \\
4 \\
\end{array}$ & 1.23714353 \\
\hline & April & 579 & $\begin{array}{c}664.432350 \\
6 \\
\end{array}$ & $\begin{array}{c}754.449060 \\
3 \\
\end{array}$ & $\begin{array}{c}574.415640 \\
9 \\
\end{array}$ & $\begin{array}{c}- \\
22.5041774 \\
\end{array}$ & $\begin{array}{c}551.911463 \\
5 \\
\end{array}$ & $\begin{array}{r}733.788 \\
8 \\
\end{array}$ & 4.67850371 \\
\hline & Mei & 439 & $\begin{array}{c}647.345880 \\
5 \\
\end{array}$ & $\begin{array}{c}733.028424 \\
3 \\
\end{array}$ & $\begin{array}{c}561.663336 \\
7 \\
\end{array}$ & -21.420636 & $\begin{array}{c}540.242700 \\
7 \\
\end{array}$ & $\begin{array}{r}10250.0 \\
8 \\
\end{array}$ & $\begin{array}{r}23.0621186 \\
1 \\
\end{array}$ \\
\hline & Juni & 312 & $\begin{array}{c}605.676704 \\
4 \\
\end{array}$ & $\begin{array}{c}707.558080 \\
3 \\
\end{array}$ & $\begin{array}{c}503.795328 \\
4 \\
\end{array}$ & -25.470344 & $\begin{array}{c}478.324984 \\
5 \\
\end{array}$ & 27664 & $\begin{array}{r}53.3092898 \\
9 \\
\end{array}$ \\
\hline & Juli & 557 & $\begin{array}{c}546.941363 \\
5 \\
\end{array}$ & 675.434737 & $\begin{array}{c}418.447990 \\
1 \\
\end{array}$ & $\begin{array}{c}- \\
32.1233434 \\
\end{array}$ & $\begin{array}{c}386.324646 \\
7 \\
\end{array}$ & $\begin{array}{r}29130.0 \\
8 \\
\end{array}$ & $\begin{array}{r}30.6418946 \\
7 \\
\end{array}$ \\
\hline & Agustus & 473 & $\begin{array}{c}548.953090 \\
8 \\
\end{array}$ & $\begin{array}{c}650.138407 \\
7 \\
\end{array}$ & $\begin{array}{c}447.767773 \\
9 \\
\end{array}$ & 25.2963292 & $\begin{array}{c}422.471444 \\
7\end{array}$ & $\begin{array}{r}2553.13 \\
5 \\
\end{array}$ & $\begin{array}{r}10.6825698 \\
4 \\
\end{array}$ \\
\hline & $\begin{array}{c}\text { Septemb } \\
\text { er }\end{array}$ & 452 & $\begin{array}{c}533.762472 \\
6 \\
\end{array}$ & $\begin{array}{c}626.863220 \\
7 \\
\end{array}$ & $\begin{array}{c}440.661724 \\
6 \\
\end{array}$ & -23.275187 & $\begin{array}{c}417.386537 \\
6 \\
\end{array}$ & $\begin{array}{r}1198.09 \\
2 \\
\end{array}$ & $\begin{array}{r}7.65784567 \\
2 \\
\end{array}$ \\
\hline & Oktober & 576 & $\begin{array}{c}517.409978 \\
1 \\
\end{array}$ & $\begin{array}{c}604.972572 \\
2 \\
\end{array}$ & 429.847384 & 21.8906485 & $\begin{array}{c}407.956735 \\
5 \\
\end{array}$ & $\begin{array}{r}28238.5 \\
4 \\
\end{array}$ & $\begin{array}{r}29.1741778 \\
6 \\
\end{array}$ \\
\hline & $\begin{array}{c}\text { Novembe } \\
r\end{array}$ & 567 & $\begin{array}{c}529.127982 \\
5 \\
\end{array}$ & $\begin{array}{c}589.803654 \\
2 \\
\end{array}$ & $\begin{array}{c}468.452310 \\
7 \\
\end{array}$ & 15.1689179 & $\begin{array}{c}453.283392 \\
8 \\
\end{array}$ & $\begin{array}{r}12931.4 \\
7 \\
\end{array}$ & $\begin{array}{r}20.0558390 \\
1 \\
\end{array}$ \\
\hline & $\begin{array}{c}\text { Desembe } \\
r\end{array}$ & 496 & 536.702386 & $\begin{array}{c}579.183400 \\
6 \\
\end{array}$ & $\begin{array}{c}494.221371 \\
4 \\
\end{array}$ & 10.6202537 & $\begin{array}{c}483.601117 \\
7 \\
\end{array}$ & $\begin{array}{r}153.732 \\
3 \\
\end{array}$ & 2.49977465 \\
\hline 2018 & Januari & 705 & $\begin{array}{c}528.561908 \\
8 \\
\end{array}$ & $\begin{array}{c}569.059102 \\
2 \\
\end{array}$ & $\begin{array}{c}488.064715 \\
4 \\
\end{array}$ & 10.1242984 & 477.940417 & $\begin{array}{r}51556.0 \\
5 \\
\end{array}$ & $\begin{array}{r}32.2070330 \\
5 \\
\end{array}$ \\
\hline & Februari & 674 & 563.849527 & $\begin{array}{c}568.017187 \\
2\end{array}$ & $\begin{array}{c}559.681866 \\
9 \\
\end{array}$ & 1.04191504 & $\begin{array}{c}558.639951 \\
8 \\
\end{array}$ & $\begin{array}{r}13307.9 \\
4 \\
\end{array}$ & $\begin{array}{r}17.1157341 \\
5 \\
\end{array}$ \\
\hline & Maret & 656 & $\begin{array}{c}585.879621 \\
6\end{array}$ & $\begin{array}{c}571.589674 \\
1\end{array}$ & $\begin{array}{c}600.169569 \\
2\end{array}$ & $\begin{array}{c}3.57248688 \\
6\end{array}$ & $\begin{array}{c}603.742056 \\
1 \\
\end{array}$ & $\begin{array}{r}2730.89 \\
3 \\
\end{array}$ & $\begin{array}{r}7.96614999 \\
1 \\
\end{array}$ \\
\hline & April & 558 & $\begin{array}{c}599.903697 \\
3 \\
\end{array}$ & $\begin{array}{c}577.252478 \\
7 \\
\end{array}$ & $\begin{array}{c}622.554915 \\
9 \\
\end{array}$ & $\begin{array}{c}5.66280464 \\
4 \\
\end{array}$ & $\begin{array}{c}628.217720 \\
5 \\
\end{array}$ & $\begin{array}{r}4930.52 \\
8 \\
\end{array}$ & $\begin{array}{r}12.5838208 \\
8 \\
\end{array}$ \\
\hline & Mei & 447 & $\begin{array}{c}591.522957 \\
8 \\
\end{array}$ & $\begin{array}{c}580.106574 \\
6 \\
\end{array}$ & $\begin{array}{c}602.939341 \\
1 \\
\end{array}$ & $\begin{array}{c}2.85409582 \\
3 \\
\end{array}$ & 605.793437 & $\begin{array}{r}25215.3 \\
6 \\
\end{array}$ & $\begin{array}{r}35.5242588 \\
3 \\
\end{array}$ \\
\hline & Juni & 317 & $\begin{array}{c}562.618366 \\
3 \\
\end{array}$ & $\begin{array}{c}576.608932 \\
9 \\
\end{array}$ & $\begin{array}{c}548.627799 \\
7 \\
\end{array}$ & $\begin{array}{c}- \\
3.49764166 \\
\end{array}$ & 545.130158 & $\begin{array}{r}52043.3 \\
7 \\
\end{array}$ & $\begin{array}{r}71.9653495 \\
3 \\
\end{array}$ \\
\hline
\end{tabular}


Aplikasi Peramalan Jumlah Pemohon Paspor Menggunakan Metode Double Exponential Smoothing Pada Kantor Imigrasi Kelas II Kota

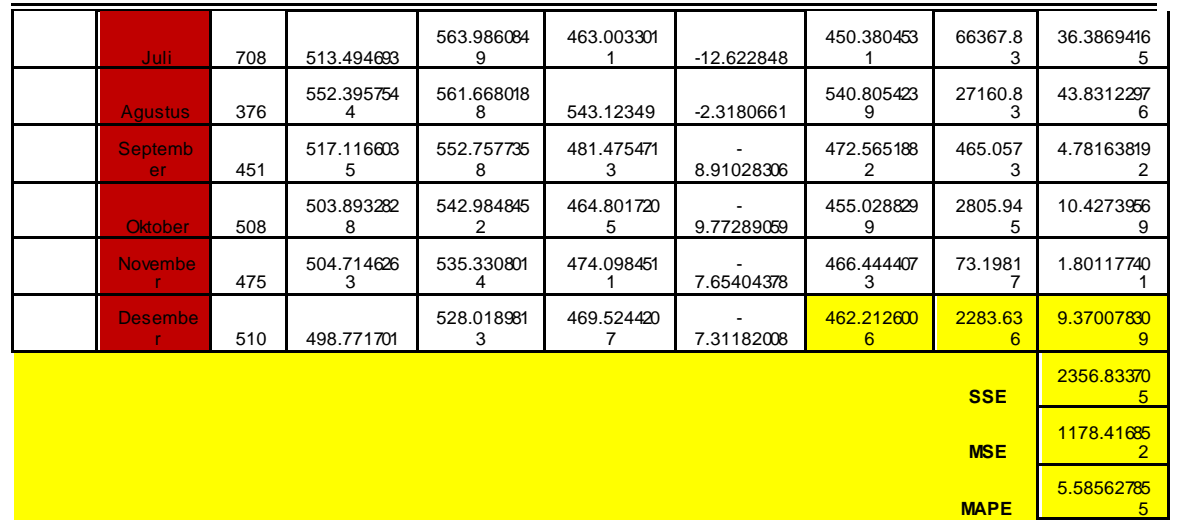

Keterangan :

Dari penelitian ini pengujian pada tahun 2018 didapatkan nilai parameter untuk double exponential smoothing adalah $a=0.2$. Dari nilai parameter tersebut didapatkan nilai SSE sebesar = 2356.833705, nilai MSE sebesar $=1178.416852$ dan MAPE sebesar $=5,585627855$.

\subsection{Desain Sistem}

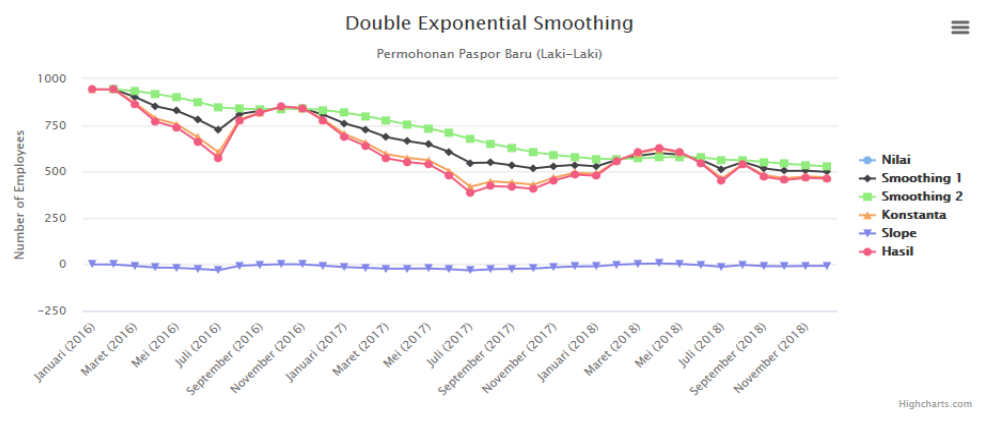

Gambar 2. Trend grafik hasil peramalan permohonan paspor baru (double exponential smoothing)

Keterangan : 
Tampilan pada halaman trend grafik hasil peramalan menampilkan grafik kenaikan dan penurunan jumlah pemohon paspor. Titik tertinggi ada di bulan januari 2016 mencapai 900 buah paspor dan titik terendah ada dibulan juli 2017 mencapai 350 buah paspor.

\section{Kesimpulan}

Berdasarkan hasil penelitian, diketahui bahwa pengujian pada tahun 2018 didapatkan nilai parameter untuk double exponential smoothing adalah $\mathrm{a}=0.2$. Dari nilai parameter tersebut didapatkan nilai SSE sebesar $=2356.833705$, nilai MSE sebesar $=1178.416852$ dan MAPE sebesar $=5,585627855$. Sehingga dapat disimpulkan bahwa metode double exponential smoothing dikategorikan sangat baik dalam peramalan jumlah pemohon paspor pada kantor imigrasi kelas II kota Lhokseumawe.

\section{Daftar Pustaka}

Cinthia, dkk. (2019). Perbandingan Double Moving Average dan Double Exponential Smoothing untuk Peramalan Jumlah Kedatangan Wisatawan Mancanegara di Bandara Ngurah Rai. Jurnal Pengembangan Teknologi Informasi dan Ilmu Komputer.

Falani, Ilham. mPenentuan Nilai Pengantar Parameter Metode Exponential Smoothing, dengan menggunakan Algoritma Geneetik dalam Meningkatkan Akurasi Forecasting, Universitas Indraprasta PGRI Jakarta, 2018.

Ida, Nuraini. Pengantar Ekonomi Mikro, Universitas Muhammadiyah Malang, Press 2009

Kim, S., \& Kim, H. (2016). A new metric of absolute percentage error for intermittent demand forecasts. International Journal of Forecasting.

Makridakis, S., Wheelwright, S. C., \& McGee, V. E. (1998). Metode dan Aplikasi Peramalan (terjemahan). Jakarta: Binarupa Ksara. 
Aplikasi Peramalan Jumlah Pemohon Paspor Menggunakan Metode

Double Exponential Smoothing Pada Kantor Imigrasi Kelas II Kota

Lhokseumawe

$\overline{\text { Nasdaniar. (2017). Evaluasi Pelayanan Pembuatan Paspor (Surat }}$ Perjalanan) di Kantor Imigrasi Kelas I Kota Samarinda. ejournal Administrasi Negara, 6051- 6063.

Winardi J, Paul A. Pengantar Ilmu Ekonomi, an introductory analysis, Budi Kemuning, 6051-6063 